\title{
Characteristic Duties of Critical Care Nurses in Japan: A Time-Study Comparison with Neurology Ward Nurses
}

\author{
Yumiko Yatomi1, Tomoko Inoue ${ }^{2}$, Yuko Kawamoto ${ }^{1}$ \\ ${ }^{1}$ Department of Critical Invasive-Palliative Care Nursing, Graduate School of Health Care Science, \\ Tokyo Medical and Dental University, Tokyo, Japan \\ ${ }^{2}$ National College of Nursing Japan, Tokyo, Japan \\ Email: Yatomo.cc@tmd.ac.jp
}

How to cite this paper: Yatomi, Y., Inoue, T. and Kawamoto, Y. (2016) Characteristic Duties of Critical Care Nurses in Japan: A Time-Study Comparison with Neurology Ward Nurses. Open Journal of Nursing, 6, 1038-1051.

http://dx.doi.org/10.4236/ojn.2016.612099

Received: November 14, 2016

Accepted: December 25, 2016

Published: December 28, 2016

Copyright $\odot 2016$ by authors and Scientific Research Publishing Inc. This work is licensed under the Creative Commons Attribution International License (CC BY 4.0).

http://creativecommons.org/licenses/by/4.0/

\section{(c) (i) Open Access}

\begin{abstract}
Background: The importance of the acute phase in hospitals has been increasing. While administering high-level critical care, the working styles of critical care nurses, the types of clinical care they provide, and the way in which they prioritize tasks, remain unclear. Aim of this study was to elucidate the characteristic duties of critical care nurses through a comparison with neurological ward nurses. Methods: We recorded the duties of critical care nurses and neurology ward nurses (10 each) using a time-study design. Duties were measured separately by action, classified using a classification table, and differences between the two groups were compared. Results: No differences in the number of actions were observed between the two groups. The top five items that required the most time for critical care nurses were, "Movement", "Administration and oxygen management", "Handover process/Doctor's rounds", "Preparation for entry and exit management of patients", and "Bed bathing (for bedbound patients)". Of the 195 items, significant differences between the groups were noted for 34 items, while the duties of critical care nurses were best characterized by bed bathing (for bedbound patients), changing position, confirmation of infusion tubes, handover process/doctor's rounds, and preparation for entry and exit management of patients. Conclusion: A characteristic of critical care nurses is that they must remain near patients and perform tasks while moving only a short distance. Moreover, the promotion of tasks while communicating with physicians is presumed to play a role in the promotion of team medicine. Furthermore, much time was spent caring for patients in bed, and a lot of time was devoted to the preparation and finalizing of treatments and care, suggesting the possibility that more time can be spent on caring for patients through a revision of duties.
\end{abstract}




\section{Keywords}

Critical Care Nurse, Time-Study, Neurology Ward Nurse

\section{Introduction}

Due to the arrival of a rapidly aging society, improved survival rates due to advances in medical technology, and the shortening of hospital stays, the importance of the acute phase in hospitals has been increasing. Due to the increasing number of elderly operative patients, and patients who require care for the acute exacerbation of chronic disease, there are now many patients who require complex and advanced care. The number of patients in critical condition has also been increasing. While administering highdegree critical care, critical care nurses care for patients in critical conditions, and perform a wide variety of tasks [1]. Although the behavior of critical care nurses may seem natural, it is dictated by a number of complex factors, such as the needs and preferences of each individual patient and their situation, knowledge obtained by nurses, difficulty of implementation, and the balance of priorities and preferences [2] [3] [4]. When providing support, there are often various types of restrictions that exist, for example, patient-related factors such as decreased function and exacerbation or instability of condition; nurse-related factors such as the quality and ability of nurses; and environmental factors, such as insufficient staffing levels and the inability to receive instructions due to the absence of physicians [1]. Under such complex circumstances, it is unclear what sort of working styles critical care nurses have and what sort of clinical care they are able to provide.

Therefore, we focused on neurology ward patients when examining the nature of critical care nursing practice. Neurology patients, who are in critical condition and are highly dependent on medical treatment, often have disorders that persist after treatment, and in many cases the cause of the problem and the appropriate treatment cannot be identified, resulting in slow and uncertain progress. As their conditions progress, patients are forced to rethink their lives and lifestyles, and often have to give up a large amount of autonomy to medical practitioners and family members [5] [6] [7]. It is important for neurology nurses to be supportive of patients when making decisions and undertaking lifestyle changes as a result of their conditions. Moreover, an assessment of the amount of nursing duties [8] revealed that nursing needs scores, and the degree of supporting patients required to perform daily living activities was higher in the neurol-

ogy ward and intensive care unit (ICU); characteristic nursing duties included: caring for patients resistant to treatment without leaving them unaccompanied on the ward, and time taken for generalized physical care in the ICU. A time-study of nursing tasks in the ICU [9] revealed that ICU nurses performed various tasks, with the emphasis on tasks differing depending on the experience of the nurses. It can be predicted that the environment surrounding nurses, the quality of the nurses themselves, patients, treatment, and care environment, change the level of support that is provided. 


\section{Aim}

The principal aim of the present study was to elucidate the characteristic duties of critical care nurses through a comparison with neurology ward nurses, who are said to deliver an especially high degree of care to patients highly dependent on medical treatment.

\section{Methods}

\subsection{Participants}

The participants were 10 nurses who worked in a critical care unit and 10 who worked on a neurology ward at a university hospital in the Tokyo region of Japan. The nurses were divided equally into two groups: those with five or more years of clinical experience, and those with less than five years of experience. The participants were selected randomly. The critical care unit contained 12 beds, and there were many patients planned to be admitted, as well as patients whose condition suddenly changed during hospitalization. There were 46 beds in the neurology ward, but of these, neurology patients used 42 and cardiology patients used four.

\subsection{Investigation Period}

November 2009-August 2010.

\subsection{Date Collection Method}

The present study employed a time-study design, in which the actions of nurses were observed. The actions of each nurse were measured by the second during working hours on weekdays (8:00 to 17:00). Each time an action changed, it was counted as one action. The days of measurement were selected randomly from days in which staff duties were performed. However, nursing actions that required the bathing of patients while talking were regarded as a series of nursing actions, and were regarded as "Bed bathing". The classification of recorded actions was based on the model developed by Numazaki et al. [10]. Based on the characteristics of the observed hospital ward, and for ease of classification, we classified actions using a classification table comprised of four primary items, 32 secondary items, and 195 tertiary items (Table 1). The recipients of nursing actions were classified in four groups: patients of charge, other patients, both-type patients (charge and other), and non-patients. Moreover, nursing actions performed in the following six locations were recorded: bedside, nurses' station, specific locations on the ward (shower room, patient toilet, examination room, device room, etc.), during movement within the ward, during movement outside the ward, and other (rest space and staff toilet).

\subsection{Analysis Method}

Using SPSS software (Ver.18), descriptive statistics and Mann-Whitney U tests were conducted to compare each measurement item between critical care nurses and neurology nurses. Statistical significance was set at $p<0.05$. 
Table 1. Nursing action classification table.

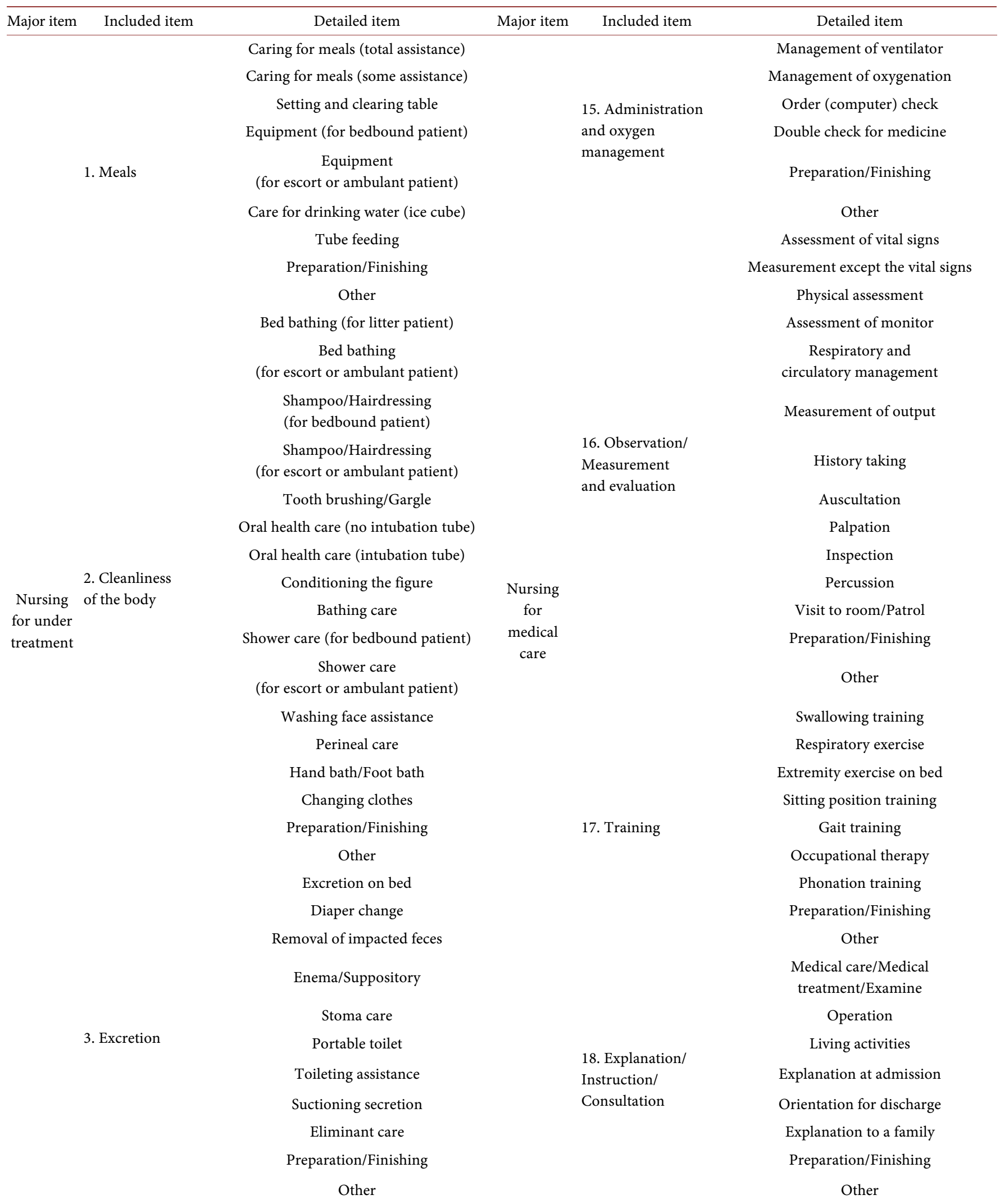




\section{Continued}

Changing position

Position adjustment of the bed

Sitting upright

4. Changing

position and

transfer

of patients

5. Environmental maintenance

\begin{abstract}
6. Other everyday life help
\end{abstract}

7. Psychological care

8. Safety

9. Comfort
Sitting position

Wheelchair

Stretcher/Bed

Standing/Walking

Preparation/Finishing

Other

Adjustment of the

medical treatment environment

Making bed

Adjustment of around the bed

Preparation/Finishing

Other

Help of the communication

Representation of other ADL

Preparation/Finishing

Other

Mental comfort

Counseling

Event/Recreation

Daily conversation/Say something

Talk with a family

Preparation/Finishing

Other

Prevention of risk (patient)

Prevention of risk (environment)

Confirmation of infusion tubes

Set tubes right

Preparation/Finishing

Other

Massage

Compress

Preparation/Finishing
Chart

19. Data collection

Documents except chart

Preparation/Finishing

Other

Handover process/Doctor's rounds

Doctors

Nurses

20. Information

exchange/

Report/

Consultation

Medical staff

Conference

Preparation/Finishing

Other

Talking by a nurse call

21. Nurse call

22. Other

Other

Nursing record (computer input)

Documents except

the nursing record

23. Record

Ward-related record

Preparation/Finishing

Other

Nurses

Student

24. Education/ Instruction

Other

nursing

Instruction to other people

Getting education

Preparation/Finishing

Other

Visitor correspondence

Medicine management

Article management

Article conveyance

25. Clerical work

Patient change management

Ward environment maintenance

Allotment of the patient

Search for person or thing

Preparation/Finishing 


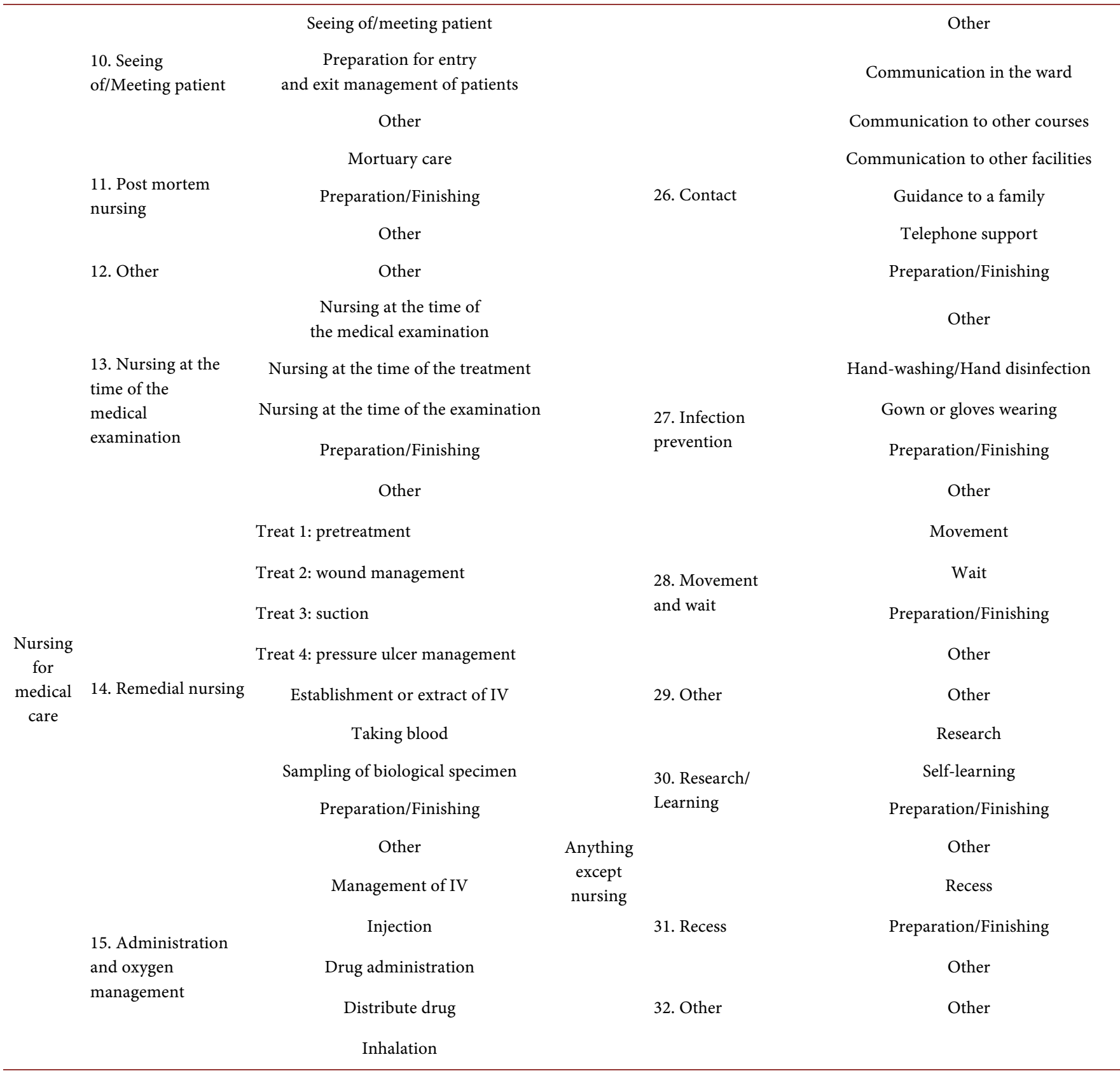

\subsection{Ethical Considerations}

The present study was approved by the institutional review board of the target facility (Approval No. 673). The participants were informed of the purpose and methods of the study, the fact that participation in the study was voluntary, and how the data was to be handled. The anonymity of participants was stressed and consent was obtained from all. Care was taken so that the standing position of the researchers during data collection did not interfere with nursing duties, and data collection was suspended or discontinued upon request by a participant. 


\section{Results}

An overview of the 10 critical care nurses and 10 neuroscience nurses is given in Table 2. No significant differences in the number of years of clinical experience, and number of years of experience in a certain field, were noted between the groups. Education background of all nurses was nursing junior college or nursing university. The mean number of patients that nurses were in charge of on the investigation day was 2.5 for critical care nurses (range: 2 - 3), and 5.2 for neurology nurses (range: 4 - 8). A total of 25 patients were charged to the critical care nurses. All 25 patients were bedbound patients, and of these, 13 were patients who were admitted or discharged from the unit. A total of 52 patients were charged to the neurology nurses. Of these 52 patients, 32 were bedbound patients, 17 were escorted patients, three were ambulatory transfer patients, and none were patients who were admitted or transferred. The mean number of actions per participant was 760.2 for critical care nurses (range: 525 - 983), and 780.4 for neurology nurses (range: 543 - 939); no significant differences between the groups were found.

\subsection{Recipients of Nursing Actions and Locations of Nursing Actions}

We compared the mean time of nursing actions between the two groups (Figure 1). The time given to patients the nurses were in charge of comprised the largest share of time in both groups ( $60 \%$ or higher). The time spent with patients other than patients of charge was significantly longer for critical care nurses (mean time: 1 hour, $16 \mathrm{mi}$ nutes 39 seconds, $p=0.028$ ). The location in which nursing actions were performed, that is, the place in which nurses were located, was at the bedside in more than $50 \%$ of cases in both groups (Figure 2). The time that neurology nurses spent at the nurses' station was significantly longer ( 1 hour 53 minutes 35 seconds, $p=0.016$ ).

\subsection{Major Items}

No significant differences between the groups were observed for the four major items (Figure 3 ). The greatest amount of time was devoted to diagnostic support nursing, followed by remedial nursing. These two items each comprised more than three hours

Table 2. Demographic profile of participants.

\begin{tabular}{ccc}
\hline Item & $\mathrm{CCN} \dagger(\mathrm{n}=10)$ & $\mathrm{NN}$ ( $\mathrm{n}=10)$ \\
\hline Sex, $\mathrm{n}(\%)$ & $9(90)$ & $9(90)$ \\
Female & $1(10)$ & $1(10)$ \\
Male & $7.2 \pm 5.9$ & $8.1 \pm 7.2$ \\
Clinical experience & $5(50)$ & $5(50)$ \\
More than 5 year, n (\%) & $5(50)$ & $5(50)$ \\
Less than 5 year, n (\%) & $3.1 \pm 1.8$ & $3.7 \pm 4.0$ \\
Domain experience &
\end{tabular}

$\dagger$ : CCN; Critical Care Nurse. $\ddagger$ : NN; Neuroscience Nurse Experience $=$ Mean \pm SD (year). 


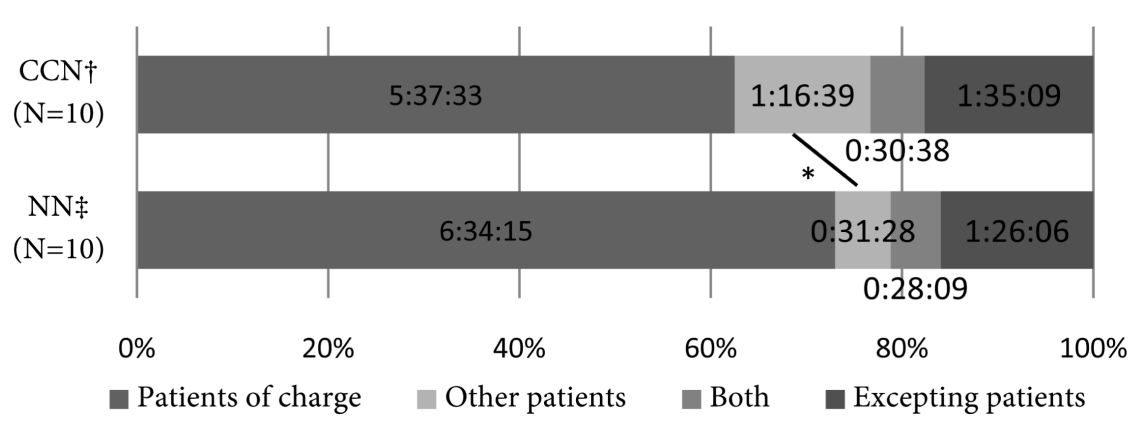

Figure 1. Average time of nursing action subject. $\dagger$ : CCN: Critical Care Nurse; $\ddagger$ NN: Neuroscience, Nurse time $=$ h:min:s, ${ }^{\star} p<0.05$ : Other patients.

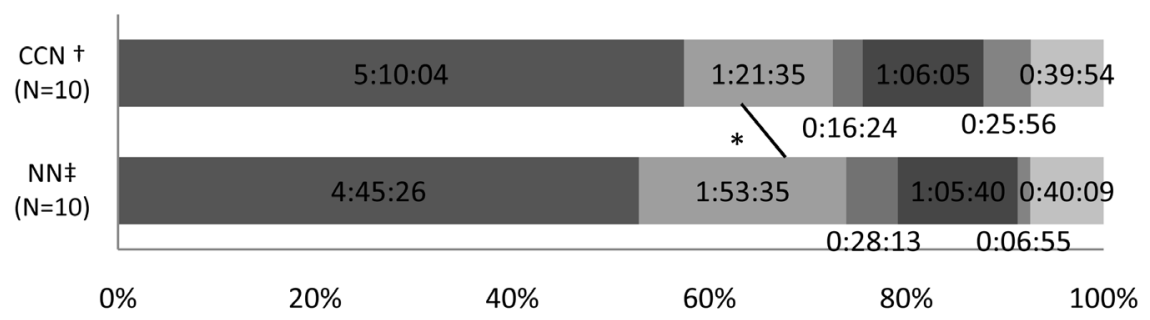

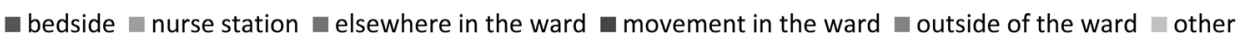

Figure 2. Average time of place to stay. $\dagger$ : CCN: Critical Care Nurse; $\ddagger$ : NN: Neuroscience Nurse time $=$ h:min: ${ }^{\star} p<0.05$ : Nurse station.

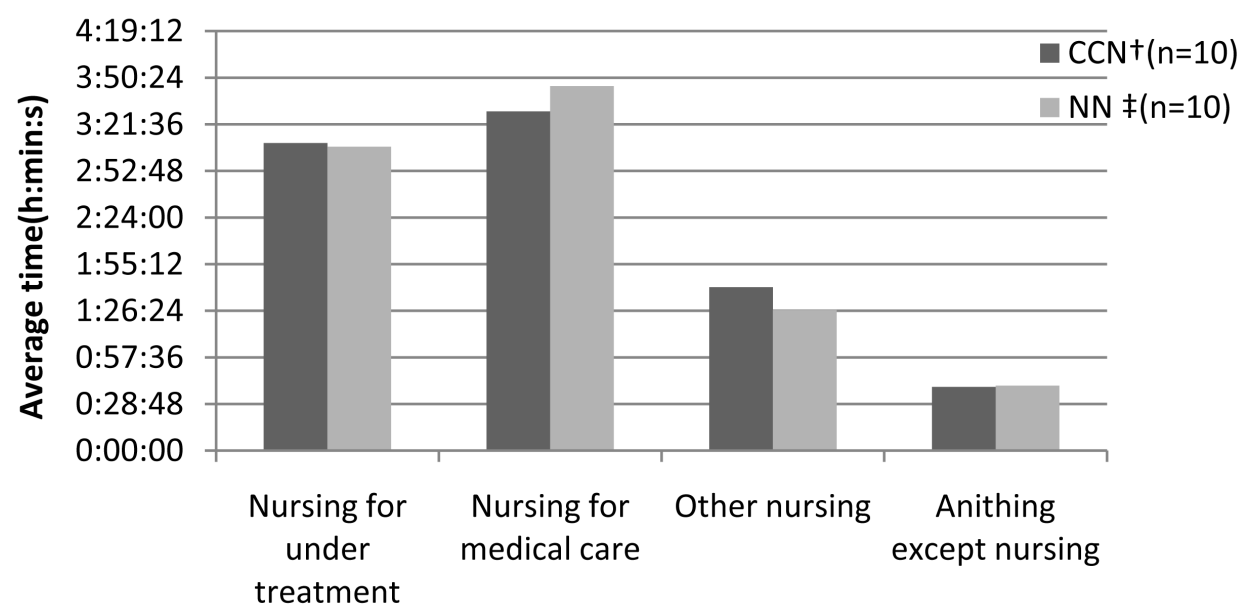

Figure 3. Average time of major item. $\dagger:$ CCN: Critical Care Nurse; $\ddagger$ NN: Neuroscience Nurse.

(75\% of the total time). Moreover, the present study investigated only lunch break time in addition to nursing actions. A mean time of 40 minutes of break time could only be taken by both groups.

\subsection{Detailed Items}

\subsubsection{Items for Which Significant Differences Were Observed}

Significant differences between the groups were observed for 34 detailed items (Table 3 ). A total of 17 of the 34 items were $p \leq 0.002$, and of these, critical care nurses spent 
Table 3. The item which is significantly different in two groups (detail item).

\begin{tabular}{|c|c|c|c|c|c|}
\hline \multirow{2}{*}{ NO } & \multirow{2}{*}{$\begin{array}{l}\text { Included } \\
\text { item }\end{array}$} & \multirow{2}{*}{ Detailed item } & \multicolumn{3}{|c|}{ Average (min: s) } \\
\hline & & & $\mathrm{CC} \dagger$ & $\mathrm{NN} \ddagger$ & $P$-value \\
\hline 1 & & Setting and cleaning table & $00: 19$ & $02: 21$ & 0.002 \\
\hline 2 & 1. Meals & Tube feeding & $00: 51$ & 03:01 & 0.024 \\
\hline 3 & & Preparation/Finishing & 05:01 & 09:05 & 0.023 \\
\hline 4 & & Bed bathing (for bedbound patient) & 29:00 & $07: 51$ & 0.002 \\
\hline 5 & 2. Cleanliness & Oral health care (no intubation tube) & $00: 55$ & $08: 54$ & 0.005 \\
\hline 6 & of the body & Conditioning the figure & $00: 23$ & $02: 53$ & 0.004 \\
\hline 7 & & Perineal care & $00: 43$ & $08: 47$ & 0.002 \\
\hline 8 & 3. Excretion & Diaper change & 00:00 & $02: 58$ & 0.001 \\
\hline 9 & & Toileting assistance & 00:00 & 07:11 & 0.000 \\
\hline 10 & 4. Changing & Changing position & $15: 57$ & $10: 25$ & 0.041 \\
\hline 11 & position and & Wheelchair & 01:41 & 09:22 & 0.006 \\
\hline 12 & transfer of patients & Standing/Walking & $00: 30$ & 03:15 & 0.022 \\
\hline 13 & & Prevention of risk (environment) & 00:00 & $00: 32$ & 0.005 \\
\hline 14 & 8. Safety & Confirmation of infusion tubes & $13: 20$ & $00: 34$ & 0.000 \\
\hline 15 & & Preparation/Finishing & 00:06 & $01: 43$ & 0.008 \\
\hline 16 & & Seeing of/meeting patient & $07: 23$ & 00:00 & 0.005 \\
\hline 17 & 10. Seeing of/Meeting patient & $\begin{array}{l}\text { Preparation for entry and exit } \\
\text { management of patients }\end{array}$ & $30: 54$ & 00:00 & 0.000 \\
\hline 18 & 13. Nursing at the time & Nursing at the time of the examination & 01:53 & $00: 20$ & 0.021 \\
\hline 19 & of the medical examination & Preparation/Finishing & 01:46 & 00:29 & 0.026 \\
\hline 20 & 14. Remedial nursing & Preparation/Finishing & 01:46 & 05:15 & 0.001 \\
\hline 21 & 15. Administration & Drug administration & $02: 29$ & $10: 32$ & 0.000 \\
\hline 22 & and oxygen management & Inhalation & 00:01 & $00: 35$ & 0.000 \\
\hline 23 & & Management of ventilator & 01:15 & $00: 10$ & 0.002 \\
\hline 24 & 16. Observation/Measurement & Order (computer) check & 10:09 & 28:59 & 0.000 \\
\hline 25 & and evaluation & Double check for medicine & 08:18 & 01:59 & 0.001 \\
\hline 26 & & Assessment of vital signs & 02:00 & 10:02 & 0.001 \\
\hline 27 & 19. Data collection & Documents except chart & 00:48 & $01: 51$ & 0.013 \\
\hline 28 & & Handover process/Doctor's rounds & $35: 05$ & $12: 32$ & 0.000 \\
\hline 29 & $\begin{array}{l}\text { 20. Information } \\
\text { exchange/Report/ }\end{array}$ & Doctors & 07:49 & 04:05 & 0.028 \\
\hline 30 & Consultation & Medical staff & $00: 29$ & $02: 03$ & 0.023 \\
\hline 31 & & Conference & $11: 00$ & $21: 40$ & 0.023 \\
\hline 32 & 21. Nurse call & Preparation/Finishing & 00:00 & $00: 31$ & 0.002 \\
\hline 33 & 27. Infection prevention & Gown or gloves wearing & 01:31 & 07:02 & 0.001 \\
\hline 34 & 28. Movement and wait & Wait & $01: 55$ & 03:32 & 0.023 \\
\hline
\end{tabular}

$\dagger$ : CCN: Critical Care Nurse; $\ddagger$ NN: Neuroscience Nurse. Mann-Whitney U test, critical $p$-value $p<0.05$. 
more time on the following six: "Bed bathing (for bedbound patient)", "Confirmation of infusion tubes", "Preparation for entry and exit management of patients", "Management of ventilators", "Double checking for medicine", and "Handover process/Doctor's rounds". By contrast, the 11 items that neurology nurses spent more time on were as follows: "Setting and clearing tables", "Perineal care", "Diaper change", "Toileting assistance", "Preparation/Finishing (Remedial nursing)", "Drug administration”, "Inhalation”, "Order (computer) check”, “Assessment of vital signs”, "Preparation/Finishing (Nurse call)", "Gown or gloves wearing”.

\subsubsection{Items on Which Time Was Spent}

The actions taking the longest mean time in the two groups are shown in Table 4. The item that took the greatest amount of time in both groups was "Movement", followed by "Preparation and clearance of drugs and oxygen". The items following these that required the most time for critical care nurses were, "Handover process/Doctor's rounds", "Preparation for entry and exit management of patients", and "Bed bathing (for bedbound patients)". For the neurology nurses, the items that took the longest time were "Order (computer) check", "Conference", and "Preparation/Finishing (Cleanliness of the body)".

\section{Discussion}

\subsection{Working Environment Characteristics for Critical Care Nurses}

The results of the present study indicate that the time critical care nurses give to provide care for other patients is longer, and that duties are often performed at the bedside,

Table 4. Ranking of average time (detailed item).

\begin{tabular}{|c|c|c|c|c|}
\hline \multirow{2}{*}{$\begin{array}{c}\text { Ranking } \\
1\end{array}$} & \multicolumn{2}{|l|}{$\mathrm{CC} \uparrow$; Detailed item (min:s) } & \multicolumn{2}{|c|}{ NNł; Detailed item (min:s) } \\
\hline & Movement & $43: 22$ & Movement & $40: 33$ \\
\hline 2 & $\begin{array}{c}\text { Preparation and clearance of } \\
\text { drugs and oxygen }\end{array}$ & $35: 55$ & $\begin{array}{c}\text { Preparation and clearance of } \\
\text { drugs and oxygen }\end{array}$ & $36: 55$ \\
\hline 3 & $\begin{array}{l}\text { Handover process/ } \\
\text { Doctor's rounds }\end{array}$ & $35: 05$ & Order (computer) check & $28: 59$ \\
\hline 4 & $\begin{array}{c}\text { Preparation for entry and } \\
\text { exit management of patients }\end{array}$ & $30: 54$ & Conference & $21: 40$ \\
\hline 5 & $\begin{array}{c}\text { Bed bathing } \\
\text { (for bedbound patients) }\end{array}$ & 29:00 & $\begin{array}{l}\text { Preparation/Finishing } \\
\text { (Cleanliness of the body) }\end{array}$ & $20: 18$ \\
\hline 6 & $\begin{array}{l}\text { Nursing record } \\
\text { (computer input) }\end{array}$ & $27: 52$ & $\begin{array}{l}\text { Nursing record } \\
\text { (computer input) }\end{array}$ & $18: 16$ \\
\hline 7 & $\begin{array}{l}\text { Information exchange } \\
\text { between nurses }\end{array}$ & $24: 32$ & Treat 3: suction & $17: 30$ \\
\hline 8 & Changing position & $15: 57$ & $\begin{array}{c}\text { Information exchange } \\
\text { between nurses }\end{array}$ & $17: 03$ \\
\hline 9 & $\begin{array}{l}\text { Preparation/Finishing } \\
\text { (cleanliness of the body) }\end{array}$ & $15: 37$ & $\begin{array}{c}\text { Handover process/ } \\
\text { Doctor's rounds }\end{array}$ & $12: 32$ \\
\hline 10 & Confirmation of infusion tubes & $13: 20$ & $\begin{array}{l}\text { Daily conversation/ } \\
\text { Say something }\end{array}$ & $12: 15$ \\
\hline
\end{tabular}

†: CCN: Critical Care Nurse; $\neq$ NN: Neuroscience Nurse. 
or in the vicinity of the bed. Previous research investigating nurses' range of movement in the ICU [9] found that $46 \%$ of daily tasks were performed in the area near the patient, with similar results found for movement around the bed. By comparison, the neurology nurses spent much more time at the nurses' station preparing treatments, conferring with colleagues, and organizing records. These findings reflect the characteristics of critical care patients who are often connected to monitors and artificial respirators, having many tubes (such as infusion tubes and excretion drains) connected to the body, meaning that there are few times that they are left alone. The area in which critical care nurses need to operate is small, which is why the time needed for movement did not change in comparison with neurology nurses, as critical care nurses were constantly moving across shorter distances. Moreover, in critical care practice, it is often difficult for a single nurse to give care, and actions such as cleaning, changing body position, and performing suction often require two or more nurses. Therefore, the environment of the nurses is set up so that there are few patients of charge, all of whom can be easily watched by the nurses, even when care is given to other patients. Furthermore, the bedside function of the nurses' station is distributed at bedside. Items used for treatment are placed at the bedside, and there is a treatment table next to the bed to prepare infusion fluid; as a result, it is an environment in which efficient communication with other staff members is facilitated. Based on the results of the present study, it can be concluded that the work environment of critical care nurses is unique, and the nurses are positioned so that movement occurs within a short distance.

\subsection{Characteristic Work Duties of Critical Care Nurses}

\subsubsection{Always Remaining near the Patient}

In comparison to neurology nurses, critical care nurses spent much more time on tasks related to bed bathing for bedbound patients, confirmation of infusion tubes, performing double checks of drugs and devices, and the management of artificial respirators. Therefore, it can be understood that critical care nurses care for patients while managing medical devices and tubes. The results revealed that in comparison with neurology nurses, who often directly talked with and came into close contact with patients through performing actions such as toileting assistance, administering drugs, and assessment of vital signs, critical care nurses observed the condition of patients while remaining at their side so that the nurses could provide care at any time. The results are consistent with those of previous studies, which indicate that critical care nurses perform comparatively less direct physical and personal care of patients and engage in less conversation [11]. It was revealed that reaming in close proximity to the patient was a very significant and important strategy used by critical care nurses when performing duties, even when not directly coming into contact or speaking with patients. Studies that have investigated the experiences of patients receiving critical care [12] have reported that when in a critical condition, patients feel peace of mind when a nurse is nearby watching over them, and have a desire to fight the illness. Although continually being near the patient may create the risk of violating the privacy of patients, it is ne- 
cessary to consider how to behave while understanding the significance of remaining near the patient.

\subsubsection{Impetus of Team Medicine}

The neurology nurses took a certain amount of time in the nurses' station, and spent a certain amount of time conferring with other members of the medical team, or each other. By contrast, critical care nurses consulted with physicians and other nurses about the condition of patients between performing care longer than in conferences, and spent more time on preparation for entry and exit management of patients. It is clear that critical care nurses did not generally leave the sides of patients, and performed their tasks while communicating with medical staff during short periods. In order to adapt to changes in the state of the patient, quick discussions with others were observed. Previous studies [13] [14] have indicated the role of nurses in promoting interdisciplinary coordination and collaboration in the field of critical care medicine. Based on the working style and duties of critical care nurses, they involve other medical staff members and perform care as a team while watching over the patients; it can be predicted that this is the impetus for the promotion of team medicine.

\subsubsection{Tasks That Can Be Substituted}

The results of the present study revealed that preparing for and finishing movement and preparation for drug administration and oxygen management took, the greatest amount of time for nurses in both groups. This is because the items have different applications between the groups, with critical care nurses moving continuously within a short distance and often performing the preparation and cleanup of many transfusions. Neurology nurses spent much more time moving from the bed to guide patients to the toilet, and moved across long hallways; preparation and cleanup of medicine also took a longer time. Moreover, a characteristic specific to critical care nurses was much time being dedicated to the acceptance of operative patients and the preparation and finishing of movement between the critical care unit and the hospital wards. Although there was movement that was associated with preparation and cleanup that required expertise, many tasks were performed on behalf of another person, or could be shortened through adjustment. It can be said that a review of staffing and operations is needed, and that and subsequent revisions and adjustments of the environment, such as the rearranging of items, is required.

\section{Conclusion}

Characteristics of critical care nurses are that they must perform tasks while moving across a short distance in the unit, be continually ready to observe and be ready to respond to the needs of patients by remaining near them, and communicate with physicians and other nurses while performing their tasks. Critical care nurses constantly remained near patients, and it can be presumed that they played a role in adjusting the team while being able to quickly make judgments and respond to patients. Moreover, much time was spent performing care for patients in bed, but much time was devoted 
to the preparation and finishing of treatment and care, suggesting the possibility that more time can be spent on performing assessments and caring for patients through a revision of duties.

\section{Limitations and Further Research}

As the present study was a survey limited to the wards of a single facility, there is a possibility of specific outcomes. In the future, it is necessary to conduct investigations that include a variety of facilities and critical care centers. Moreover, investigations that focus on characteristics as a result of experience are needed.

\section{Acknowledgements}

The authors would like to thank the participants and the graduate students of the section of Critical Invasive-Palliative Care Nursing, Graduate School of Health Care Science, Tokyo Medical and Dental University. This work was supported by Public Trust Fumiko Yamaji professional nursing education research grants fund.

\section{References}

[1] Bucknall, T. (2003) The Clinical Landscape of Critical Care: Nurses' Decision-Making. Journal of Advanced Nursing, 43, 310-319. https://doi.org/10.1046/j.1365-2648.2003.02714.x

[2] Radwin, L.E. (1995) Knowing the Patient: A Process Model for Individualized Interventions. Nursing Research, 44, 364-370. https://doi.org/10.1097/00006199-199511000-00008

[3] Benner, P., Hooper-Kyriakidis, P.L. and Stannard DInoue, T. (Translation Supervisor) (2005) Clinical Wisdom and Intervention in Critical Care: A Thinking-In-Action Approach. Igaku-Shoin Ltd., 15-17. (In Japanese)

[4] Nakafuji, M. (2005) A Description of Skulled Practices of Expert Nurses in Critical Care. The Japanese Journal of Nursing Research, 38, 121-134. (In Japanese)

[5] Haahr, A., Kirkevold, M., Hall, E.O. and Ostergaard, K. (2011) Living with Advanced Parkinson's Disease: A Constant Struggle with Unpredictability. Journal of Advanced Nursing, 67, 408-417. https://doi.org/10.1111/j.1365-2648.2010.05459.x

[6] King, S.J., Duke, M.M. and O’Connor, B.A. (2009) Living with Amyotrophic Lateral Sclerosis/Motor Neurone Disease (ALS/MND): Decision-Making about 'Ongoing Change And Adaptation'. Journal of Clinical Nursing, 18, 745-754. https://doi.org/10.1111/j.1365-2702.2008.02671.x

[7] Barreca, S. and Wilkins, S. (2008) Experiences of Nurses Working in a Stroke Rehabilitation Unit. Journal of Advanced Nursing, 63, 36-44. https://doi.org/10.1111/j.1365-2648.2008.04648.x

[8] Odaira, R., Sakurai, M., Sasaki, M., et al. (2006) Research in Necessity of Nursing Care. Medical Journal of Nagaoka Red Cross Hospital, 12, 7-16. (In Japanese)

[9] Murano, T., Kobayashi, H., Kinoshita, Y., et al. (2008) Movement of Nurses Work in the Intensive Care Unit. Tokyo Healthcare University, 1, 25-29. (In Japanese)

[10] Numasaki, H., Kasahara, S., Ishii, A., et al. (2004) Data Management in Time and Motion Study. The Japanese Journal of Nursing Research, 37, 33-46. (In Japanese)

[11] Abbey, M., Chaboyer, W. and Mitchell, M. (2012) Understanding the Work of Intensive 
Care Nurse: A Time and Motion Study. Australian Critical Care, 25, 13-22.

https://doi.org/10.1016/j.aucc.2011.08.002

[12] Yumiko, Y. (2012) Characteristics of Supports among Critical Care Nurses for Patient's Daily Life Behavior. Ochanomizu Kangogaku Journal, 7, 1-19. (In Japanese)

[13] Hajewski, C.J. and Shirey, M.R. (2014) Care Coordination: A Model for the Acute Care Hospital Setting. Journal of Nursing Administration, 44, 577-585. https://doi.org/10.1097/NNA.0000000000000129

[14] Cropley, S. and Sanders, E.D. (2013) Care Coordination and the Essential Role of the Nurse. Creative Nursing, 19, 189-194. https://doi.org/10.1891/1078-4535.19.4.189

Submit or recommend next manuscript to SCIRP and we will provide best service for you:

Accepting pre-submission inquiries through Email, Facebook, LinkedIn, Twitter, etc.

A wide selection of journals (inclusive of 9 subjects, more than 200 journals)

Providing 24-hour high-quality service

User-friendly online submission system

Fair and swift peer-review system

Efficient typesetting and proofreading procedure

Display of the result of downloads and visits, as well as the number of cited articles

Maximum dissemination of your research work

Submit your manuscript at: http://papersubmission.scirp.org/

Or contact ojn@scirp.org 